\title{
Development of Roundabout Delay Models Using Traffic Simulation Programs: A Case Study at Al-Mansour City, Iraq
}

\author{
(Pembangunan Model Kelewatan di Bulatan Menggunakan Program Simulasi Trafik Penyerupaan: \\ Kajian Kes di Bandar Al-Mansour, Iraq) \\ Alla Jaber Essa*, Amiruddin Ismail, Ali Emad Jehad, Ameer Abdul Adheem Hussein \& Abdullah Hayal Khalaf \\ Department of Civil \& Structural Engineering, Universiti Kebangsaan Malaysia, Malaysia \\ Hussin A.M. Yahia \\ Department of Civil Engineering, Middle East College, Oman
}

\begin{abstract}
Due to the increased number of vehicles, shopping centers and rapid growth population of Al-Mansour city, daily trips have been increasing besides generating traffic congestion in major roundabouts in the city. Those will make developing an imperial delay model in roundabouts important due to the traffic and geometric influences. Therefore, two major roundabouts have been selected in the city to be taken as a case study. Geometric features for the selected roundabouts have been measured accurately by satellite images via ArcGIS. Traffic and geometric data analysis indicate that both are significantly important on delay models. The delay time produced by SIDRA and SYNCHRO has been compared with the delay time measured from the field. A significant difference in delay for roundabouts is noticed. This difference could be attributed to the difference in driver behaviour. Ideal saturation flow is the main factor related to driver behaviour, so it adjusted to be the average of the saturation flow measured from the field (2200 vphgpl).
\end{abstract}

Keywords: Traffic Delay Mode; Roundabout; SIDRA; SYNCHRO; Linear Regression Model

\section{INTRODUCTION}

Studies show that traffic demand and congestions have grown rapidly in Baghdad in the recent years. As no single solution or technology that can solve the traffic congestion issues all by itself, optimization strategies by using simulation models can be applied to signal timing and road capacity analysis to tackle the problem (Al-Jabbar et al. 2011; Bertini \& Cassidy 2002; Yousif \& Zhang 2011).

The quality and accuracy of the simulation models have been improved over the past years while new concepts and technologies added to the field. There are many types of simulation model's characteristics, such as static or dynamic, deterministic or stochastic, microscopic or macroscopic (Wang \& Prevedouros 1996). Different backgrounds and different algorithms will define each simulation model development. Every model is ideal for its situation and also has its strengths and weaknesses; therefore, the selected program should satisfy the analyst needs for his objectives and simulate the aspects of the study area (Russell et al. 2000).

SIDRA INTERSECTION has been used in much research to evaluate and improve roundabout performance measures. (Sisiopiku \& Oh 2001) stated with the aid of SIDRA simulation analysis of variations in volume levels, turning volume splits, number of approach lanes, and lane widths that roundabouts are the best alternative designs for intersections with two-lane approaches that carry heavy through and/or left traffic turning volumes. While (Muley \& Al-Mandhari 2014) evaluate the performance of a multi-lane four legged modern roundabout operating in Muscat using SIDRA model. The performance measures include Degree of Saturation (DOS), average delay, and queue lengths. The geometric and traffic data were used for model preparation sensitivity analysis for general and roundabout parameters was performed, amongst lane width, cruise speed, inscribed diameter, entry radius and entry angle showed that inscribed diameter is most crucial factor affecting delay and DOS.

An empirical approach was used to develop a delay model as a function of the influencing factors based on a time interval of $15 \mathrm{~min}$. The analysis indicated that geometric variables have significant effects on the roundabout entry delay (Al-Omari et al. 2004).

In other hand, SYNCHRO/SimTraffic has been introduced by (Shaaban \& Kim 2015) whose compares the performance of the two simulation tools (SimTraffic and VISSIM) in modeling dual lane and triple lane roundabouts under different scenarios such as traffic volume, proportion of left turning movement, and proportion of trucks in the traffic flow. Most of the performance of modern roundabouts' studies that deal with a single lane which are slightly congested. However, lack of existing studies that deals with terms of capacity and delay (Chen \& Lee 2016).

The relationship between the entry capacity of an approach and the circulating flow has been introduced at a macroscopic level as statistical methods or at a microscopic level as probabilistic methods and the relationship has been described in many developed models (Camus et al. 2004). 


\section{METHODOLOGY}

The data collection phase was aimed at assembling all data that would be required to model the traffic flow conditions at the study sites. All traffic data have been collected during morning and evening peak hours (7:00-9:00, 17:00-19:00) in five working days. Figure 1 shows two roundabouts with four approaches in each roundabout. Roundabout (1) represents a high traffic demand with an oval shape of central-island with traffic control system. While roundabout (2) consider being a normal shape central-island roundabout with no traffic control system with less traffic demand. The traffic volumes, traffic composition, and the volume of turning movements have been abstracted from manual recording for each approach at roundabout (1) and roundabout (2). The network average traffic volumes (vehicles/hour) for both Roundabouts are shown in Tables 1 and 2. All roundabouts geometry dimensions have been measured manually in site and automatically via ArcGIS.

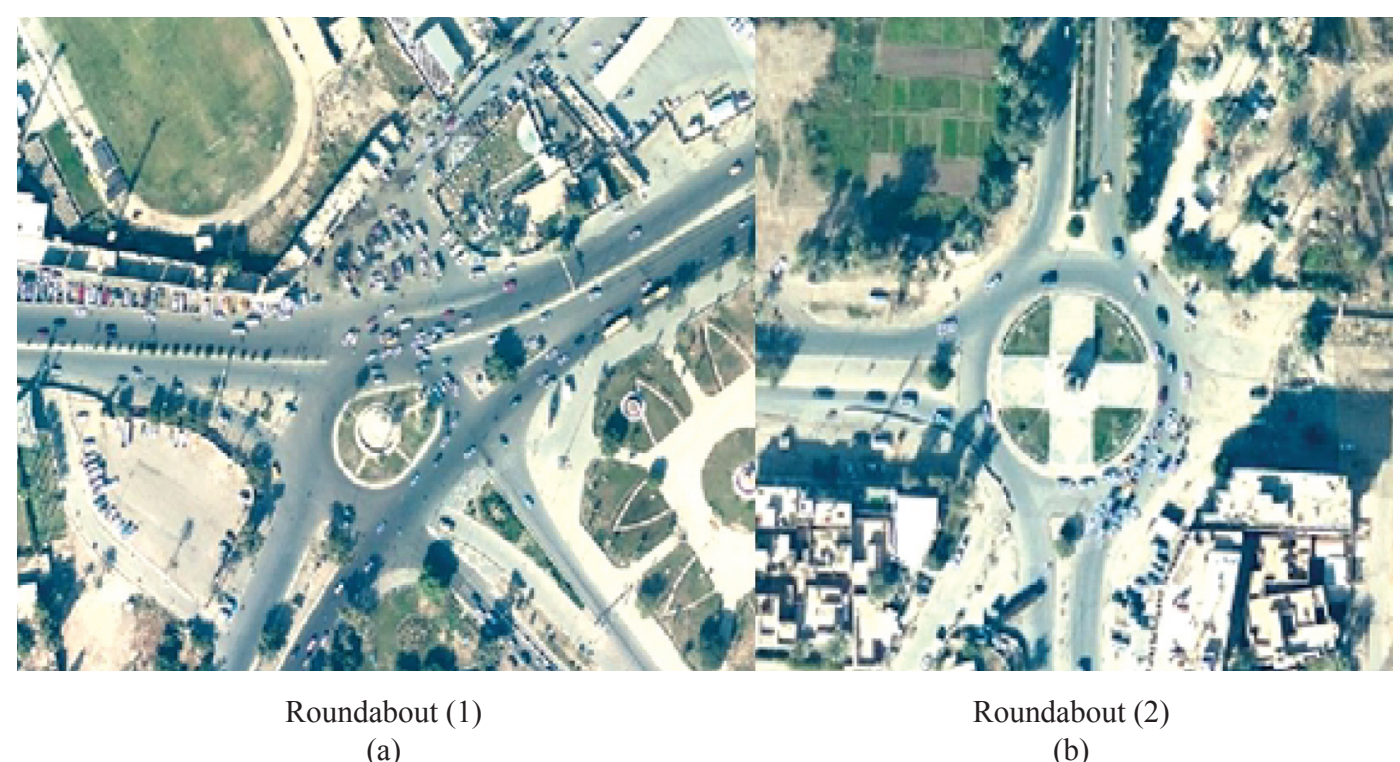

FIGURE 1. Overview of the study area by using ArcGIS; (a) Roundabout (1) and (b) Roundabout (2)

TABLE 1. Traffic volume data for roundabout (1)

\begin{tabular}{|c|c|c|c|c|c|c|c|c|c|c|c|c|c|c|c|c|c|c|c|c|}
\hline \multirow[b]{2}{*}{ Time } & \multicolumn{6}{|c|}{ Damascus street } & \multicolumn{4}{|c|}{ Al Zaytoon street } & \multicolumn{5}{|c|}{ Al Kindi street } & \multicolumn{5}{|c|}{ Al Mansour street } \\
\hline & $\begin{array}{l}\stackrel{5}{9} \\
\stackrel{9}{9}\end{array}$ & 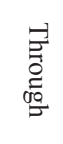 & 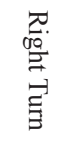 & 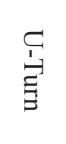 & $\stackrel{\overrightarrow{0}}{\stackrel{\vec{D}}{ \pm}}$ & $\begin{array}{l}\underset{0}{9} \\
\stackrel{9}{G} \\
\Xi\end{array}$ & 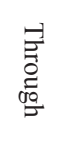 & 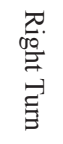 & 売 & $\stackrel{\vec{\circ}}{\vec{D}}$ & $\begin{array}{l}\underset{0}{9} \\
\stackrel{9}{9} \\
\text { 晋 }\end{array}$ & 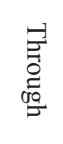 & 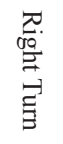 & 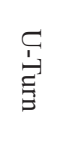 & $\stackrel{\vec{\circ}}{\ddot{E}}$ & 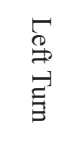 & 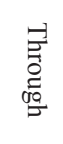 & 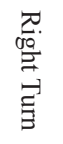 & 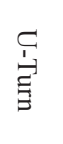 & 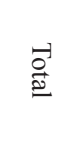 \\
\hline $7: 00-7: 30$ & 346 & 332 & 440 & 328 & 1446 & 377 & 359 & 376 & 414 & 1526 & 372 & 421 & 342 & 351 & 1486 & 369 & 418 & 355 & 451 & 1593 \\
\hline 7:30 - 8:00 & 362 & 360 & 384 & 366 & 1472 & 387 & 358 & 362 & 336 & 1443 & 436 & 383 & 415 & 396 & 1630 & 340 & 449 & 379 & 358 & 1526 \\
\hline 8:00 - 8:30 & 385 & 372 & 387 & 401 & 1545 & 382 & 388 & 387 & 395 & 1552 & 322 & 345 & 356 & 411 & 1434 & 326 & 363 & 371 & 321 & 1381 \\
\hline $8: 30$ - 9:00 & 426 & 352 & 412 & 394 & 1584 & 451 & 408 & 372 & 391 & 1622 & 349 & 408 & 383 & 402 & 1542 & 325 & 382 & 326 & 420 & 1453 \\
\hline $17: 00-17: 30$ & 349 & 421 & 387 & 400 & 1557 & 365 & 324 & 401 & 369 & 1459 & 465 & 438 & 401 & 408 & 1712 & 346 & 384 & 433 & 398 & 1561 \\
\hline $17: 30-18: 00$ & 338 & 403 & 417 & 415 & 1573 & 383 & 385 & 401 & 334 & 1503 & 374 & 444 & 382 & 410 & 1610 & 373 & 391 & 418 & 412 & 1594 \\
\hline $18: 00-18: 30$ & 386 & 384 & 379 & 433 & 1582 & 338 & 413 & 365 & 418 & 1534 & 307 & 367 & 406 & 390 & 1470 & 386 & 310 & 397 & 397 & 1490 \\
\hline $18: 30$ - 19:00 & 409 & 393 & 388 & 348 & 1538 & 384 & 431 & 371 & 390 & 1576 & 408 & 349 & 439 & 374 & 1570 & 374 & 419 & 338 & 387 & 1518 \\
\hline
\end{tabular}


TABLE 2. Traffic volume data for roundabout (2)

\begin{tabular}{|c|c|c|c|c|c|c|c|c|c|c|c|c|c|c|c|c|c|c|c|c|}
\hline \multirow[b]{2}{*}{ Time } & \multicolumn{6}{|c|}{ Derage street } & \multicolumn{4}{|c|}{ Al Mothana street } & \multicolumn{5}{|c|}{ Al Mansour street } & \multicolumn{5}{|c|}{ Abu Jaafar Al Mansour street } \\
\hline & $\begin{array}{l}\stackrel{5}{9} \\
\underset{\exists}{G}\end{array}$ & 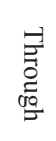 & 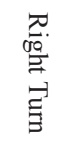 & $\begin{array}{l}\stackrel{C}{\mathfrak{G}} \\
\stackrel{G}{\exists}\end{array}$ & $\begin{array}{l}\overrightarrow{0} \\
\vec{D}\end{array}$ & $\underset{\Xi}{\stackrel{5}{\Xi}}$ & 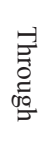 & 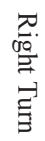 & 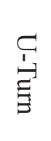 & $\begin{array}{l}\stackrel{-0}{D} \\
\stackrel{D}{E}\end{array}$ & 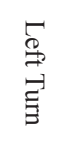 & 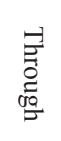 & 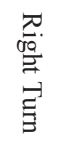 & 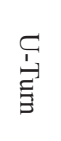 & $\stackrel{\vec{\circ}}{\stackrel{\oplus}{ٍ}}$ & $\begin{array}{l}\stackrel{6}{9} \\
\stackrel{\Xi}{G}\end{array}$ & 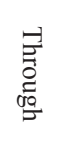 & 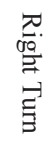 & 罳 & $\begin{array}{l}\vec{O} \\
\stackrel{\Xi}{\Xi}\end{array}$ \\
\hline $7: 00-7: 30$ & 103 & 184 & 204 & 102 & 593 & 67 & 54 & 56 & 49 & 226 & 182 & 236 & 139 & 202 & 759 & 218 & 144 & 229 & 200 & 791 \\
\hline $7: 30-8: 00$ & 127 & 217 & 198 & 91 & 633 & 63 & 56 & 80 & 35 & 234 & 191 & 193 & 163 & 221 & 768 & 200 & 154 & 239 & 226 & 819 \\
\hline $8: 00-8: 30$ & 106 & 189 & 228 & 86 & 609 & 75 & 65 & 62 & 34 & 236 & 207 & 198 & 190 & 183 & 778 & 191 & 136 & 235 & 236 & 798 \\
\hline $8: 30-9: 00$ & 110 & 203 & 223 & 94 & 630 & 54 & 58 & 72 & 43 & 227 & 229 & 196 & 140 & 248 & 813 & 235 & 131 & 224 & 209 & 799 \\
\hline $17: 00-17: 30$ & 136 & 194 & 201 & 94 & 625 & 66 & 68 & 66 & 48 & 248 & 225 & 241 & 190 & 191 & 847 & 219 & 128 & 229 & 223 & 799 \\
\hline $17: 30-18: 00$ & 125 & 199 & 228 & 97 & 649 & 71 & 56 & 73 & 46 & 246 & 187 & 227 & 177 & 197 & 788 & 205 & 143 & 236 & 213 & 797 \\
\hline $18: 00-18: 30$ & 142 & 183 & 201 & 99 & 625 & 71 & 67 & 63 & 49 & 250 & 187 & 221 & 164 & 216 & 788 & 218 & 125 & 198 & 240 & 781 \\
\hline $18: 30-19: 00$ & 113 & 193 & 195 & 93 & 594 & 77 & 63 & 58 & 45 & 243 & 245 & 217 & 170 & 220 & 852 & 231 & 143 & 191 & 225 & 790 \\
\hline
\end{tabular}

The main geometric features of roundabout such as (entry width, exit width, entry radius, entry angle, effective lane width, circulating width, splitter island width, inscribed circle diameter, and central island diameter) have been measured to be considered some variables information for the delay model. The main geometric features of the selected roundabouts are shown in Table 3.

TABLE 3. Geometric features for the selected roundabouts

\begin{tabular}{|c|c|c|c|c|c|c|c|c|c|c|c|c|}
\hline 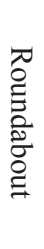 & 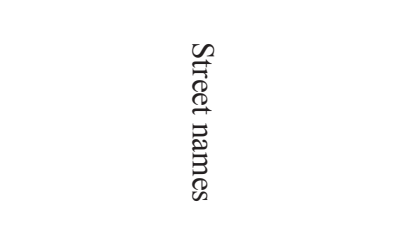 & 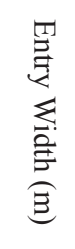 & 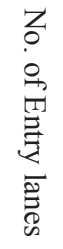 & 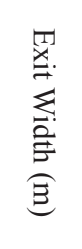 & 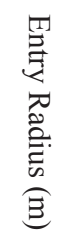 & 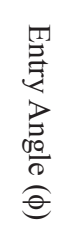 & 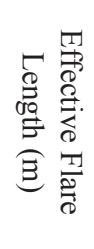 & 态总. & 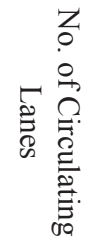 & 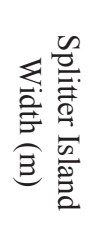 & 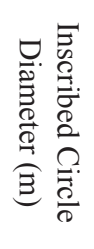 & 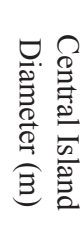 \\
\hline \multirow[t]{2}{*}{1} & Damascus/Al Kindi & 18.6 & $4 / 4$ & 22.6 & 28.8 & 36 & 18 & 20 & 4 & 8.3 & 67 & 27 \\
\hline & Al Zaytoon/Al Mansour & 18.6 & $4 / 3$ & 11.7 & 20.3 & 36 & 9 & 20 & 4 & 5.3 & 67 & 27 \\
\hline \multirow[t]{2}{*}{2} & Al Mothana/Abu Jaafar Al M. & 16.1 & $3 / 3$ & 18.4 & 55 & 56 & 18.2 & 17 & 4 & 5.3 & 54 & 68 \\
\hline & Derage/Al Mansour & 16.1 & $3 / 3$ & 18.4 & 55 & 56 & 18.2 & 17 & 4 & 5.3 & 54 & 68 \\
\hline
\end{tabular}

Roundabouts (1) and (2) have been simulated by using SIDRA INTERSECTION 6 in order to show the performance measurement of roundabouts with The default value of the basic saturation flow rate used by SIDRA INTERSECTION 6 model is 1950 (tcuphgpl). Al-Eigaidy (2004) suggested that in order to simulate the ideal saturation flow measured from the field in Baghdad city, 1950 (tcuphgpl) will be changed to 2200 (tcuphgpl). Figure 2 shows the network layout as printed from SIDRA INTERSECTION 6.

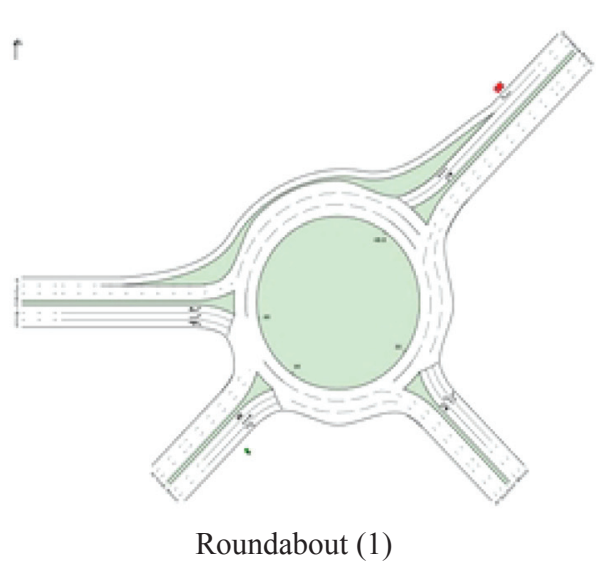

(a)

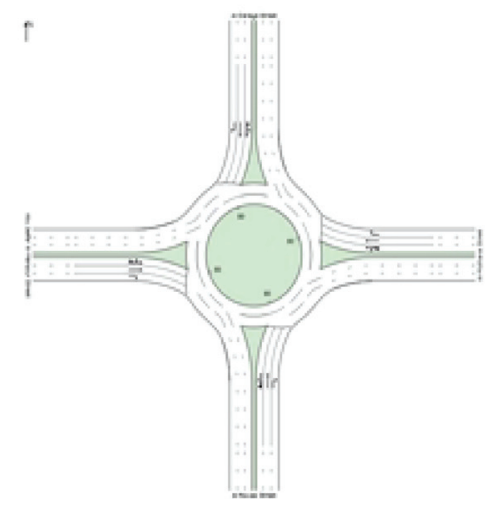

Roundabout (2)

(b)

FIGURE 2. Network layout as printout by SIDRA INTERSECTION; (a) Roundabout (1) and (b) Roundabout (2) 
SYNCHRO software has the ability to simulate the traffic stream in roundabouts with a realistic map background that have been imported from ArcGIS images. There are many files types that support SYNCHRO (Trafficware 2014).
SYNCHRO can imported any satellite image and then adjusted by input scale automatically; the image scale is adjusted by measuring distance as shown in Figure 3.

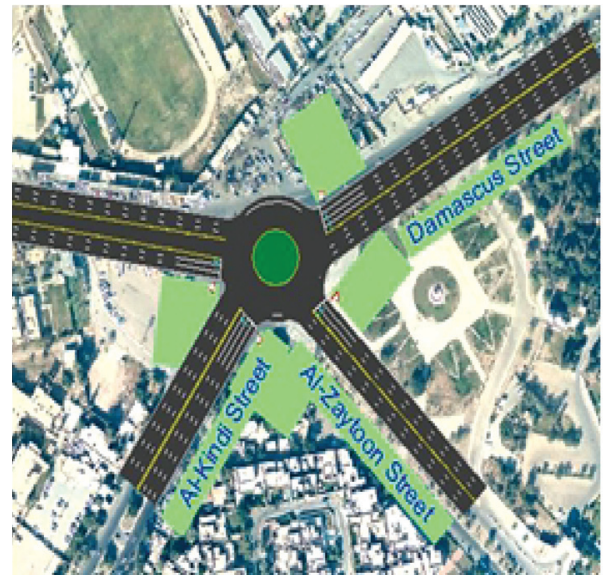

Roundabout (1)

(a)

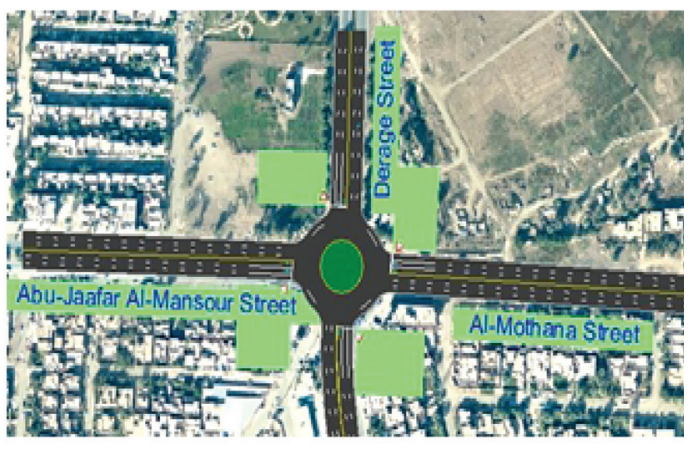

Roundabout (2)

(b)

FIGURE 3. Network layout as printout by SYNCHRO; (a) Roundabout (1) and (b) Roundabout (2)

To analyze any intersection, movement traffic volume is essential especially turning movement volume. Turning movement volume can be measured by tracking vehicles that entering the intersection from the approach leg to the exit leg. This process can be done easily by recruiting more than one observer to a traffic signal intersection due to the clearness and open area of an intersection, this process can be quite difficult with a roundabout with high traffic demands. Also the distance between the entry and exit points is often to out of range for one observer's eye beside that one observer can't track too many vehicles at the same time at the roundabout (Robinson et al. 2000).

The Federal Highway Administration (FHWA) and Highway Capacity Manual 2010 (TRB 2010) recommended that the roundabouts turning movement estimation must be derived from collected traffic volume data. Which requires various factors such as the entering, exiting, circulating, and right turns for each leg of the traffic circle, as in Figure 1 , while traffic volume that entering the roundabout were determined from Equations 1 and 2, respectively, in addition to each term definition is shown graphically in Figure 4 (TRB 2010; NCHRP 2010).

$$
\begin{aligned}
\text { Volume }_{\text {west-east }}= & \text { Volume }_{\text {west },} \text { entry }+ \text { Volume }_{\text {east }} \text { exit }- \\
& \text { Volume }_{\text {west-south }}-\text { Volume }_{\text {south-east }}- \\
& \text { Volume }_{\text {west }} \text { circle } \\
\text { Volume }_{\text {west-north }}= & \text { Volume }_{\text {west },} \text { entry }- \text { Volume }_{\text {west-east }}- \\
& \text { Volume }_{\text {west-south }}
\end{aligned}
$$

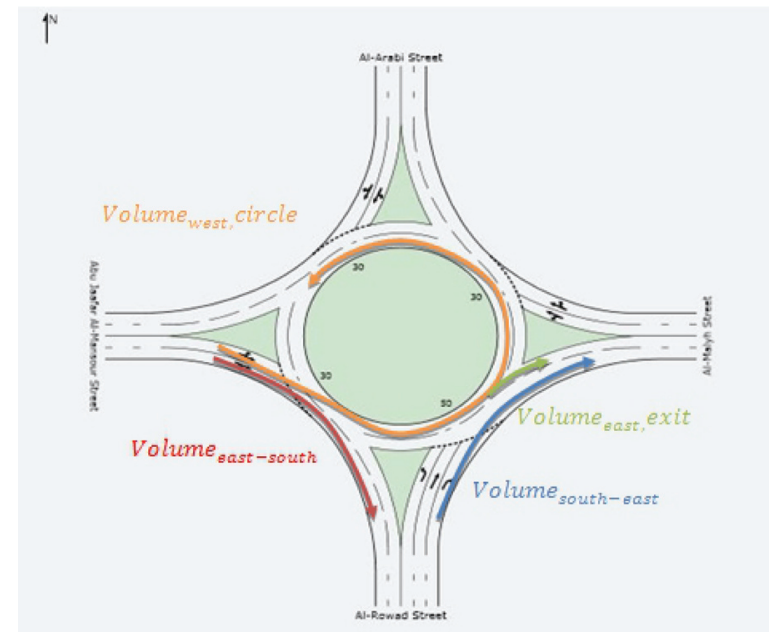

FIGURE 4. Turning movements per approach

RESULTS AND DISCUSSION

DEVELOPMENT OF ROUNDABOUT DELAY MODELS

In this paper, the empirical approach will be used to develop roundabout delay models for as a function of traffic volumes and geometric factors. Several variables are used to simulate the traffic conditions that affect total delay (geometric and control delay) such as (volume of vehicles in the circulating roadway, volume of left turning vehicles in the subject entry, and volume of weaving vehicles in the subject entry). Table 4 shows the traffic volume variables for both roundabouts. Also, there are significant impacts on total delay by geometric features such as (central island diameter, entry width, circulating length, and entry radius) were included in model building. The definition of each variable is shown graphically in Figure 5. 
TABLE 4. Traffic volume variables for both roundabouts

\begin{tabular}{ccccc}
\hline Roundabout & Street names & $\begin{array}{c}\text { Volume of vehicles } \\
\text { in the circulating } \\
\text { roadway }(\mathrm{v} / \mathrm{h})\end{array}$ & $\begin{array}{c}\text { Volume of left turning } \\
\text { vehicles in the } \\
\text { subject entry }(\mathrm{v} / \mathrm{h})\end{array}$ & $\begin{array}{c}\text { Volume of weaving } \\
\text { vehicles in the } \\
\text { subject entry }(\mathrm{v} / \mathrm{h})\end{array}$ \\
\hline \multirow{2}{*}{1} & Damascus & 6689 & 708 & 2094 \\
& Al Zaytoon & 7540 & 764 & 2231 \\
& Al Kindi & 7653 & 808 & 2359 \\
Al Mansour & Derage & 7474 & 709 & 2385 \\
& Al Mothana & 2772 & 230 & 824 \\
& Al Mansour & 2722 & 130 & 324 \\
& Abu Jaafar Al Mansour & 3176 & 373 & 1225 \\
\hline
\end{tabular}

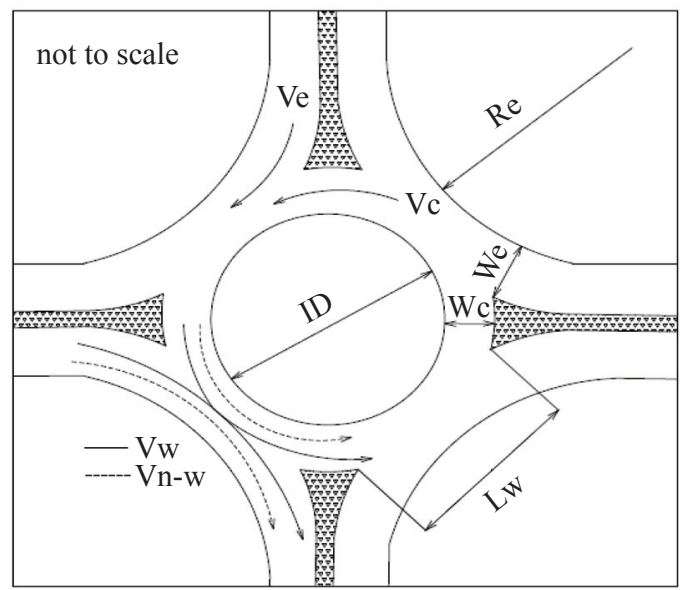
$\mathrm{V}_{\mathrm{c}}$ : Volume of vehicles in the roadway (veh/hr)
$\mathrm{R}_{\mathrm{e}}$ : Entry radius of the subjected approach (m)
$\mathrm{W}_{\mathrm{e}}$ : Width of entry $(\mathrm{m})$
$\mathrm{W}_{\mathrm{c}}$ : Width of circulating roadway $(\mathrm{m})$
$\mathrm{V}_{\mathrm{e}}$ : Volume of entry in the subjected entry $(\mathrm{v} / \mathrm{h})$
$\mathrm{V}_{\mathrm{w}}$ : Volume of weaving vehicle in the subjected entry $(\mathrm{v} / \mathrm{h})$
$\mathrm{V}_{\mathrm{n}-\mathrm{w}}$ : Volume of non-weaving vehicle in the subjected entry $(\mathrm{v} / \mathrm{h})$
$\mathrm{L}_{\mathrm{w}}$ : Length of weaving $(\mathrm{m})$
ID: Inscribed diameter $(\mathrm{m})$

FIGURE 5. Roundabout variables definition

Source: (Ambros et al. 2016)

MODEL BUILDING

When building the model, these criteria can be used in a stepwise manner. That is, by either adding consecutive variables to the model (forward search method), or by removing variables from an initial set (backward search method), or combination of them (stepwise method) (Marques de Sá 2007). With this technique, variables are sequentially added to the model if they pass a threshold test. Variables that have been added might become redundant at a later stage, however, so variables are also tested for possible deletion at each step. These decisions are based on the outcome of partial-F tests (Ryan 2007).

\section{LINEAR REGRESSION MODEL}

Circulating traffic volume $\left(\mathrm{V}_{\mathrm{C}}\right)$ and entry radius $\left(\mathrm{R}_{\mathrm{e}}\right)$ are used in model (A), which represent $\mathrm{R}^{2}$ equals to 0.130 which is not reliable due to very low value with $P$-value of 0.0706 to model (A) and 0.067 and 0.078 to the dependent variables respectively. Table 4 shows the regression results while Equation 3 shows values of coefficients for $(\mathrm{Vc}, \mathrm{Re}$, and Intercept).

Delay $($ sec. $/$ veh $)=0.258 V_{C}-6.574 R_{e}+288.788$
TABLE 4. Regression results for model (A)

\begin{tabular}{cccc}
\hline & Coefficient & $t$-value & $p$-value \\
\hline Intercept & 288.788 & 0.090 & 0.051 \\
$\mathrm{~V}_{\mathrm{C}}$ & 0.258 & 0.617 & 0.067 \\
$\mathrm{R}_{\mathrm{e}}$ & -6.574 & -0.241 & 0.078 \\
\hline
\end{tabular}

According to $P$-value, it was found that the total delay is significantly affected by more entered factors than model (a) such as weaving traffic volume $\left(\mathrm{V}_{\mathrm{w}}\right)$, left-turn traffic volume $\left(\mathrm{V}_{\mathrm{L}}\right)$, and circulating width $\left(\mathrm{W}_{\mathrm{C}}\right)$, that is why the model equation and the regression results in Table 5 shows that the left-turn traffic volume $\left(\mathrm{V}_{\mathrm{L}}\right)$ has the greatest linear association considered in delay time according to the result of $t$-value (1.256), whereas the circulating traffic volume $\left(\mathrm{V}_{\mathrm{C}}\right)$ has the less linear association with t-value of $(-0.183)$.

According to previous variables, the following linear regression model was produced for estimation of the total delay time as a model (B) with more variables for more accurate regression results. Equation 4 represents more values of coefficient due to the increase of variables in Equation 3. 


$$
\begin{aligned}
\text { Delay }= & 2.432 V_{L}-0.327 V_{C}-0.645 V_{W}+25.683 R_{e}+ \\
& 106.972 W_{C}-1857.02
\end{aligned}
$$

TABLE 5. Regression results for model (B)

\begin{tabular}{cccc}
\hline & Coefficient & $t$-value & $p$-value \\
\hline Intercept & -1857.020 & -0.434 & 0.037 \\
$\mathrm{~V}_{\mathrm{C}}$ & -0.327 & -0.183 & 0.048 \\
$\mathrm{~V}_{\mathrm{L}}$ & 2.432 & 1.256 & 0.033 \\
$\mathrm{~V}_{\mathrm{W}}$ & -0.645 & -0.448 & 0.026 \\
$\mathrm{R}_{\mathrm{e}}$ & 25.683 & 0.683 & 0.045 \\
$\mathrm{~W}_{\mathrm{c}}$ & 106.972 & 0.324 & 0.037 \\
\hline
\end{tabular}

MODEL ANALYSIS

According to models (A) and (B), it is shown that the increasing number in circulating traffic volume $\left(\mathrm{V}_{\mathrm{C}}\right)$ leads to an increase in delay time resulting to produce shorter gaps which obviously decrease the probability of gap acceptance for entering the roundabout.

The weaving traffic in the circulatory road in roundabout may produce gaps to the entry flow and cause an unnecessary delay leading to an increase in total delay time. Geometric delay will be decreased due to the increase in weaving length resulting in decreasing in vehicles speed.

There is an inverse relationship between delay time and circulating width. This is explained that when the number of lane in roundabout increase, the delay time that produced for the same roundabout will decrease due to the increasing of probability in gap acceptance since the vehicle driver intend to stay in the inner lane of the roundabout leading to keep the outer lane for merging.

\section{MODEL VALIDATION}

Model validation will determine which the selected models (A) or (B) are appropriate for the selected traffic and geometric conditions (TRB 2010). One hour traffic volume data has been collected for the selected roundabouts as a representation of Field Delay and then regressed with the delay time that predicted from the two models (A) and (B). The regression results are shown in Figure 6 and Table 6.

TABLE 6. Regression results validation for model (A) and (B)
\begin{tabular}{ccccc} 
Model & R value & R $^{2}$ & D.F & Sig. \\
\hline Model (A) & 0.594 & 0.352 & 7 & 0.121 \\
Model (B) & 0.945 & 0.893 & 7 & 0.004 \\
\hline
\end{tabular}

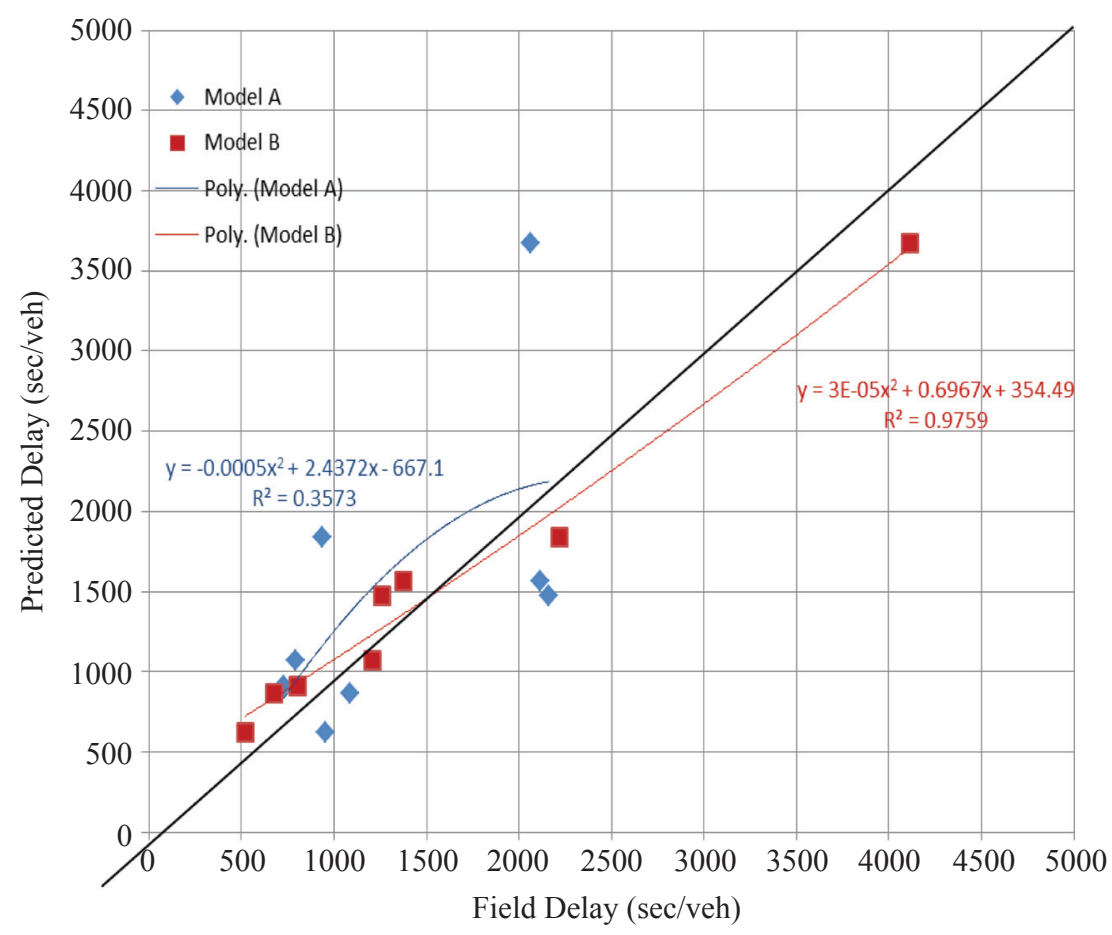

FIGURE 6. Validation of Models (A) and (B)

According to Table 4, model (A) explains about $35 \%$ of delay time that happened in roundabout resulting to designate model (A) as a non-accurate delay time prediction. Model (B) gives much higher correlation value with $89 \%$ than model (A) which leads to more accurate delay time prediction.

\section{CONCLUSION}

It can be summarized from this paper that firstly, SIDRA Intersection 6 has been used to predict delay time for the selected roundabouts and founded that the result does not have a significant difference with field delay. Regarding 
to the results between SIDRA and field, SIDRA can represent a perfect estimation for low and medium values while overestimates high values for field delay. Since SYNCHRO considered being a stochastic micro-simulation model, it is obvious to be the delay time produced by SYNCHRO has a high variation comparing to field delay. Regarding to delay estimation models, the left-turn traffic volume $\left(\mathrm{V}_{\mathrm{L}}\right)$ has the most significant impact in delay model. While increasing other factors such as traffic circulating volume and weaving volume delay time leads to an increase in delay time. However the increasing in other geometric factors like width of circulating road and the length of weaving section leads to a reduction in delay time. While, the increase in the geometric features dimension (width of circulatory road and the length weaving section) reduce the delay time. The first developed linear model (model A) has underestimates the high values of delay time, where the second developed linear model (model B) has more accurate prediction for delay time.

\section{REFERENCES}

Al-Eigaidy, S. T. 2004. Comparison Study for Saturation Flow Rate and Lost Time at Selected Intersections in Baghdad City. University of Technology.

Al-Omari, B. H., Al-Masaeid, H. R. \& Al-Shawabkah, Y. S. 2004. Development of a Delay Model for Roundabouts in Jordan. Journal of Transportation Engineering 130(1): 76-82.

Ambros, J., Novák, J., Borsos, A., Hóz, E., Kieć, M., Machciník, Š. \& Ondrejka, R. 2016. Central European comparative study of traffic safety on roundabouts. Transportation Research Procedia 14: 4200-4208.

Bertini, R. L. \& Cassidy, M. J. 2002. Some observed queue discharge features at a freeway bottleneck downstream of a merge. Transportation Research Part A: Policy and Practice 36(8): 683-697.

Camus, R., Dall'Acqua, M. \& LONGO, G. 2004. Capacity and queue modelling in un-signalised roundabouts. Proceedings of the European Transport Conference (Etc) 2004 Held 4-6 October 2004, Strasbourg, France.

Chen, X. \& Lee, M. S. 2016. A case study on multi-lane roundabouts under congestion: Comparing software capacity and delay estimates with field data. Journal of Traffic and Transportation Engineering (English Edition) 3(2): 154-165.

Huo Yamin, Xu Qin. 2011. Reasons and Possible Remedies for Baghdad City Traffic Congestion. Asce, 991-996.

Marques de Sá, J. P. 2007. Estimating Data Parameters. Dlm. Marques de Sá (pnyt.). Applied Statistics Using SPSS, STATISTICA, MATLAB and R, 81-109. Berlin, Heidelberg: Springer Berlin Heidelberg.
Muley, D. \& Al-Mandhari, H. S. 2014. Performance evaluation of Al Jame'Roundabout using SIDRA. World Academy of Science, Engineering and Technology, International Journal of Civil, Environmental, Structural, Construction and Architectural Engineering 8(12): 1296-1301.

Ryan, T. P. 2007. Modern Engineering Statistics. John Wiley $\&$ Sons.

Shaaban, K. \& Kim, I. 2015. Comparison of SimTraffic and VISSIM Microscopic Traffic simulation tools in modeling roundabouts. Procedia Computer Science 52: 43-50.

Sisiopiku, V. V. P. \& Oh, H.-U. H. 2001. Evaluation of roundabout performance using SIDRA. Journal of Transportation Engineering 127(2): 143-150.

TRB. 2010. Highway Capacity Manual. $5^{\text {th }}$ edition. Washington, D.C.: National Research Council.

Wang, Y. \& Prevedouros, P. D. 1996. Synopsis of Traffic Simulation Models. Department of Civil Engineering, University of Hawaii, Honolulu.

Yousif, M. A. \& Zhang, Z. 2011. Evaluation and Improvement of traffic operations at roundabout intersection. Third International Conference on Transportation Engineering (ICTE 2011): 210-216.

*Alla Jaber Essa Amiruddin Ismail

Ali Emad Jehad

Ameer Abdul Adheem Hussein

Abdullah Hayal Khalaf

Department of Civil \& Structural Engineering

Faculty of Engineering \& Built Environment

Universiti Kebangsaan Malaysia

43600 UKM Bangi, Selangor

Malaysia

Hussin A.M. Yahia

Department of Civil Engineering

Middle East College

Knowledge Oasis Muscat, Oman

*Corresponding author; email: alaa.j.essa@gmail.com

Received date: $28^{\text {th }}$ May 2017

Accepted date: $20^{\text {th }}$ November 2017

In Press date: $15^{\text {th }}$ December 2017

Published date: $31^{\text {st }}$ December 2017 
